\title{
A EDUCAÇÃO EM DIREITOS HUMANOS NOS CURRÍCULOS DOS CURSOS DE DIREITO NO ESTADO DE ALAGOAS: \\ um estudo de caso em um caso a ser repensado
}

\author{
Lana Lisiêr de Lima Palmeira \\ Edna Cristina do Prado \\ Carla Priscilla Barbosa Santos Cordeiro
}

Resumo

O presente trabalho busca investigar a formação propagada pelos cursos de Direito do estado de Alagoas, objetivando avaliar se atendem aos postulados da educação em direitos humanos, prevista nas políticas públicas nacionais sobre a temática. Partindo-se do pressuposto de que ainda prepondera o dogmatismo e o olhar legalista na formação dos futuros bacharéis, deixando em segundo plano a formação humanística, adotou-se como opção teórico-metodológica a abordagem de natureza qualitativa, com ênfase na revisão de literatura e na análise dos 18 currículos dos cursos de Direito ofertados em Alagoas. Assim, foi realizada uma pesquisa do tipo bibliográfica e documental. Para a análise dos dados, utilizou-se a Análise de Conteúdo de Bardin, elegendo como categorias a presença da disciplina direitos humanos nos currículos dos cursos de Direito e a proporção das disciplinas de formação humanística em relação às técnico-jurídicas. $O$ referencial teórico está pautado em autores como Tardif, Apple, Giroux, Tomaz Tadeu, Barbosa, entre outros.

Palavras-chave: educação em Direitos Humanos; cursos jurídicos; currículos; Alagoas.

\section{EDUCATION IN HUMAN RIGHTS IN THE CURRICULUM OF LAW COURSES IN THE STATE OF ALAGOAS: \\ a case study in a case to be re-thought}

\begin{abstract}
The present work seeks to investigate the training propagated by the Law courses of the State of Alagoas, aiming to evaluate if they meet the postulates of Education in Human Rights, provided for in national public policies on the theme. Starting from the assumption that dogmatism and the legalistic view still prevailed in the formation of future bachelors, leaving humanistic training in the background, the qualitative approach was adopted as a theoretical-methodological option, with emphasis on literature review and analysis of the 18 curricula of Law courses offered in Alagoas. Thus, a bibliographic and documentary research was carried out. For data analysis, Bardin Content Analysis was used, choosing as categories the presence of the Human Rights discipline in the curricula of Law courses and the proportion of Humanistic Training disciplines in relation to the technical-legal disciplines. The study had authors such as Tardif, Apple, Giroux, Tomaz Tadeu, Barbosa, among others.
\end{abstract}

Keywords: human rights education; legal courses; resumes; Alagoas.

\section{EDUCACIÓN EN DERECHOS HUMANOS EN EL CURRÍCULO DE LOS CURSOS DE DERECHO EN EL ESTADO DE ALAGOAS: un caso de estudio en un caso que hay que repensar}

Resumen

El presente trabajo busca investigar la formación propagada por los cursos de Derecho del estado de Alagoas, con el objetivo de evaluar si cumplen con los postulados de Educación en Derechos Humanos previstos en las políticas públicas nacionales en la materia. Partiendo del supuesto de que el dogmatismo y la visión legalista aún prevalecían en la formación de los futuros licenciados, dejando la formación humanista 
en un segundo plano, se adoptó el enfoque cualitativo como una opción teórico-metodológica, con énfasis en la revisión de la literatura y el análisis de los 18 planes de estudio de los cursos de Derecho que se ofrecen en Alagoas. Así, se realizó una investigación bibliográfica y documental. Para el análisis de datos se utilizó el análisis de contenido de Bardin, eligiendo como categorías la presencia de la disciplina de Derechos Humanos en los planes de estudio de los cursos de Derecho y la proporción de materias de formación humanística en relación a las técnico-legales. El marco teórico se basa en autores como Tardif, Apple, Giroux, Tomaz Tadeu, Barbosa, entre otros.

Palabras clave: educación en derechos humanos; cursos legales; reanuda; Alagoas.

\section{INTRODUÇÃO}

O ponto norteador deste estudo tem origem a partir da percepção de que os cursos de Direito em Alagoas apresentam uma formação sedimentada em currículos voltados, quase predominante, para o ensinamento de disciplinas direcionadas à formação técnico-profissional de meros aplicadores da lei, deixando como uma espécie de subformação a preparação humanística e, consequentemente, a sensibilização e o envolvimento do futuro profissional com a realidade concreta. Assim, entendeu-se relevante realizar uma pesquisa voltada à criação e difusão do saber jurídico sistematizado nos currículos de graduação em Direito do estado de Alagoas, examinando suas referenciações aos direitos humanos.

Assumindo o presente estudo a natureza qualitativa, optou-se por utilizar a Análise de Conteúdo como método de análise que objetiva a inferência de conhecimentos pertinentes às condições de produção e recepção das mensagens enunciadas. Para tanto, passou-se a trabalhar em cada fase na qual se baseia a Análise de Conteúdo, selecionando-se os documentos objeto de análise, o chamado corpus da pesquisa, aqui representado pelos 18 (dezoito) dos 19 (dezenove) currículos dos cursos de Direito ofertados no estado de Alagoas.

Ressalta-se que não foram analisados os 19 (dezenove) currículos pela impossibilidade de acesso à matriz de uma instituição de ensino superior que, além de não disponibilizar no sítio eletrônico da IES o aludido documento, recusou-se a fornecer o mesmo, sob o argumento de que aquele só era fornecido a alunos regularmente matriculados na IES.

Não se pode deslembrar que, durante a interpretação dos dados, foi necessário olhar com atenção os marcos teóricos ligados à investigação, o que foi feito ao trabalhar os conceitos de currículo à luz de autores como Michael Apple, Henry Giroux, Antônio Flávio Barbosa Moreira, assegurando sentido à interpretação do estudo, permitindo as inferências.

Também se realizou uma análise das provas do ENADE, a fim de perceber, por meio dos dados disponibilizados pelo INEP, a incidência dos conteúdos de direitos humanos nas questões de formação geral, observando índice de erros e acertos das referidas questões, estabelecendo, assim, um panorama da posição das IES do estado de Alagoas em relação ao Nordeste e ao Brasil. Vale ressaltar que se priorizou aqui trabalhar com os resultados do ENADE divulgados nos quatro últimos ciclos avaliativos, quais sejam: anos de 2006, 2009, 2012 e 2015.

Dessa forma, foi seguindo esse percurso teórico-metodológico que se construiu o presente trabalho, com o qual se espera poder contribuir para o segmento educacional, como também para várias esferas que se entrelaçam na busca de uma sociedade verdadeiramente cidadã. 


\section{O QUE É CURRÍCULO?}

Partindo-se da origem do termo "currículo" à realidade educacional, pode-se conceber a ideia de currículo como a proposta simbólica que irá definir o percurso acadêmico do estudante, diante das margens por ele estabelecidas.

Como muito bem ensina Apple (1989), currículo é poder, ideologia e cultura. Currículo é, antes de tudo, um substrato ideológico e político. E, ratificando tal raciocínio, Moreira e Silva (1999) asseveram que o currículo não é visto apenas como elemento implicado na produção de relações assimétricas de poder no ambiente interno da instituição educacional e da sociedade, mas como uma área contestada, "[...] uma arena política".

Não é excessivo declinar que em um complexo social segmentado em classes, o currículo passa a ser uma exteriorização das divergências oriundas do espaço cultural, já que a cultura é indissociável das classes sociais. Moreira e Silva (1999, p. 26), ao abordarem esse liame entre currículo e cultura, diante do que é postulado pela tradição crítica, afirmam que "[...]o currículo e a educação estão profundamente envolvidos em uma política cultural, o que significa que são tanto campos de produção ativa de cultura quanto campos contestados."

Ao trazer à cena a ideia de "relações de poder", estabelecida fica nitidamente a posição estratégica que os currículos assumem no presente estudo, já que, ao se defender a formação dos profissionais do Direito sob a perspectiva de um currículo embasado nos ideais dos direitos humanos, desconstrói-se, de certa forma, a ideia homogeneizadora que impera na atualidade de se ter uma formação altamente tecnicista, engessando os conhecimentos dentro de uma incubadora que reproduz, de forma incessante, algo que parece já estar culturalmente naturalizado: uma educação voltada a atender os anseios das classes dominantes, deixando-se em segundo plano a formação cidadã que tanto se julga necessária e urgente.

Assim, não é demais asseverar que desde o impulso inicial da teorização crítica em educação, a expressão ideologia tem se tornado uma das terminologias basilares a guiar a análise da escolarização e do currículo. Em sua obra $A$ ideologia e os aparelhos ideológicos do Estado, Althusser já acentuava uma preocupação inicial no tocante à questão da ideologia em educação, ao demonstrar que a educação representava um dos dispositivos principais por meio do qual a classe dominante reproduziria suas ideias sobre o mundo, garantindo, dessa forma, a manutenção da configuração social vigente (MOREIRA, SILVA, 1999).

Michael Apple (1997), ao se posicionar sobre o currículo, assume também a perspectiva de que nele não há espaço para a neutralidade. Faz menção às segregações, permitindo que as visões se elucidem no sentido de se pensar um currículo emancipatório, em que se tenha a propagação da autonomia em seus diversos aspectos.

Entre os subsídios centrais trazidos por Apple, tem-se a supressão de elementos repressivos, a possibilidade de uma prática curricular emancipadora e a constante ligação ao binômio "como fazer e porque fazer", por meio de uma visão crítica do currículo. De acordo com Apple (2005, p. 45), o currículo se liga ao poder e à ideologia, já que:

[...] é vital perceber que, embora nossas instituições educacionais de fato operem para distribuir valores ideológicos e conhecimento, sua influência não se resume a isso. Como sistema institucional, elas também ajudam, em última análise, a produzir o tipo de conhecimento (como se fosse um tipo de mercadoria) necessário à manutenção das composições econômicas, políticas e culturais vigentes. Chama-o "conhecimento técnico", no presente contexto. É a tensão entre distribuição e produção que em parte responde por algumas das formas de atuação das escolas no sentido de legitimar a distribuição de poder econômico e cultural existente. 
Assim, a educação se liga de forma intrínseca à cultura e à política, o que faz com que o currículo seja parte de uma tradição seletiva, isto é, escolhas de determinados grupos acerca do que seja conhecimento legítimo. Não há um conjunto neutro de conhecimentos, mas sim todo um arcabouço que expressa as tensões culturais, políticas e econômicas que entrelaçam e desentrelaçam um povo (APPLE,1997).

Dentro dessa reflexão, importante ainda trazer à cena o pensamento de Henry Giroux (1997), que, por apresentar suportes teóricos na Escola de Frankfurt, realizou contestações ao positivismo e, por via de consequência, ao reprodutivismo, defendendo que o homem é elemento ativo e a sua presença no mundo deve dar conta de realizar uma transformação social. Nessa vertente, o autor trabalha temas que também são idealizados por Paulo Freire, tais como transformação e a emancipação.

Desta maneira, Giroux se debruça sobre a importância da ideologia que é vinculada na seara escolar, como também aponta para a necessidade de uma ampla reforma educacional, em que os docentes possam ser, de fato, protagonistas da construção do conhecimento dos seus alunos, fazendo dos mesmos não apenas mero reprodutores de ideias que lhe são entregues prontas e acabadas, mas sim agentes dotados de consciência crítica e espírito reflexivo.

Nesse segmento de ideias, ressalta Giroux (1988) que é preciso entrar nesse debate declinando ser a instituição educacional um ambiente de luta e a pedagogia uma das formas de política cultural, sendo que em ambas situações é imperioso deixar nítido que a instituição educacional é uma possibilidade de dimensionar a capacidade humana, tornando as pessoas aptas a mudarem determinadas ideologias, contribuindo para a promoção do fortalecimento da democracia cidadão. É indispensável que se tenha uma pedagogia crítica, em que se repense as formas como as pessoas valoram eticamente as suas experiências e discursos.

Em outras palavras, pode-se dizer que se trata de um apelo para que se reconheça que, nas escolas, os significados são produzidos pela construção de formas de poder, experiências e identidades que precisam ser analisadas em seu sentido político-cultural mais amplo (GIROUX, 1988).

Dentro dessa proposta, o autor acentua com muita ênfase que:

Devemos enaltecer o impulso crítico e revelar a distinção entre a realidade e as condições que escondem a realidade. Esta é a tarefa que todos os educadores devem enfrentar. [...] nossa principal preocupação é abordar a questão educacional do que significa ensinar os estudantes a pensarem criticamente, a aprenderem como afirmar suas próprias experiências, e compreenderem a necessidade de lutar individual e coletivamente por uma sociedade mais justa. (GIROUX, 1997, p. 45)

Nessa necessidade acima apontada, qual seja, de se formar alunos com responsabilidade social e espírito crítico, repousa uma reflexão imediata e improtelável diante da concepção vislumbrada nessa tese, em que se defende a necessidade de preparar estudantes do Direito voltados à cidadania e não de simplesmente se lançar no mercado meros "operadores do Direito", eis que, guiados muitas vezes por um viés preponderantemente tecnicista e reducionista, esses profissionais se limitarão a "operar" o Direito, quando, na verdade, mais do que "operar" o Direito, é preciso "pensar" o Direito.

Dentro dessa corrente de ideias, Giroux vai declinar também que um desafio crucial na formação de um cidadão com senso crítico reside na própria formação recebida pelo professor, já que na visão do mesmo (1997) trabalhar o professor enfatizando apenas o conhecimento técnico é um verdadeiro desserviço à natureza do ensino e aos estudantes, pois, no lugar de desenvolverem espírito reflexivo, os futuros docentes ficam presos a metodologias que parecem negar a própria 
necessidade de pensamento crítico. Ou seja, os programas de treinamento de professores não se atrelam à necessidade de educar os alunos para que eles pensem as raízes dos problemas escolares, limitando-se a tentar entregar respostas prontas e acabadas.

Tais argumentos podem ser justapostos ao que é preceituado por Tardif (2012, p. 32), em sua obra Saberes docentes e formação profissional, quando ele levanta uma série de questionamentos, a saber:

Os professores sabem decerto alguma coisa, mas o que exatamente? Que saber é esse? São eles apenas "transmissores" de saberes produzidos por outros grupos? Produzem eles um ou mais saberes, no âmbito de sua profissão? Qual é o seu papel na definição e na seleção dos saberes transmitidos pela instituição escolar? Qual a sua função na produção dos saberes pedagógicos? As chamadas ciências da educação, elaboradas pelos pesquisadores e formadores universitários, ou os saberes e doutrinas pedagógicas, elaborados pelos ideólogos da educação, constituiriam todos os saberes dos professores?

Uma possível resposta para tais problema residiria, segundo Giroux, no que ele chama de formação de professores intelectuais, os quais teriam como característica básica ser detentores de um alicerce que os fizesse conscientes de que seu papel não se circunscreve apenas a atividades tecnicistas, mas que são, antes de tudo, agentes críticos capazes de intervir na realidade na qual se produz o que é propagado em suas práticas diuturnas.

Nessa perspectiva, tem-se que para Giroux (1997, p. 161):

Os professores podem ser vistos não simplesmente como “[...] operadores profissionalmente preparados para efetivamente atingirem quaisquer metas a eles apresentadas". Em vez disso, eles deveriam ser vistos como homens e mulheres livres, com uma dedicação especial aos valores do intelecto e ao fomento da capacidade crítica dos jovens.

Assim, dentro da visão até então esboçada, o citado autor entende que esses professores intelectuais devem ter estratégias pedagógicas que estabeleçam com os alunos relações de dialogicidade, estreitando o diálogo crítico e trazendo à discussão problematizações em torno do conhecimento, saindo assim da rotina reprodutora para uma ação mais transformadora.

Em seus exatos termos:

Os intelectuais transformadores precisam desenvolver um discurso que una a linguagem da crítica e a linguagem da possibilidade, de forma que os educadores sociais reconheçam que podem promover mudanças. Desta maneira, eles devem se manifestar contra as injustiças econômicas, políticas e sociais dentro e fora das escolas. Ao mesmo tempo, eles devem trabalhar para criar as condições que deem aos estudantes a oportunidade de tornarem-se cidadãos que tenham o conhecimento e coragem para lutar a fim de que o desespero não seja convincente e a esperança seja viável. Apesar de parecer uma tarefa difícil para os educadores, esta é uma luta que vale a pena travar. Proceder de outra maneira é negar aos educadores a chance de assumirem o papel de intelectuais transformadores (GIROUX, 1997, p. 163).

Nessa perspectiva, deve-se combater o que Paulo Freire concebe como educação bancária, ou seja, o modelo educacional que se desenvolve de forma verticalizada, em que o "dono" do conhecimento se encontra em posição de superioridade a quem não o detém que, por tal razão, fica em patamar de inferioridade, em relação de submissão e passividade, em uma verdadeira distorção do papel educacional para uma atividade de alienação. 
Como esclarece Freire (1979, p. 38):

As sociedades latino-americanas começam a se inscrever neste processo de abertura, umas mais que outras, mas a educação ainda permanece vertical. $O$ professor ainda é um ser superior que ensina a ignorantes. Isto forma uma consciência bancária. O educando recebe passivamente os conhecimentos, tornando-se um depósito do educador. Educa-se para arquivar o que se deposita. Mas o curioso é que o arquivado é o próprio homem, que perde assim seu poder de criar, se faz menos homem, é uma peça. O destino do homem deve se recriar e transformar o mundo, sendo sujeito de sua ação.

E prossegue tal raciocínio, declinando que: “[...] a consciência bancária pensa que quanto mais se dá mais se sabe. Mas a experiência revela que com este mesmo sistema só se formam indivíduos medíocres, porque não há estímulo para a criação.” (FREIRE, 1979, p. 38).

Por outro lado, deve-se prezar pela ação de um educador humanista, ação esta na qual, segundo Freire (1987, p. 35), o educador identifica-se “[...] desde logo com os educandos e deve se orientar no sentido da humanização de ambos. Do pensar autêntico e não no sentido da doação, da entrega do saber. Sua ação deve estar influenciada da profunda crença nos homens. Crença no seu poder criador."

Nessa conjuntura, é essencial alavancar a discussão em torno da abrangência do currículo não só no que se relaciona ao aspecto cognitivo, como também acercados aspectos da pessoa humana. O currículo não pode ser adstrito apenas a requisitos formais, merecendo enfoque as atitudes e as intenções daqueles que os concebem.

Gandin (2011) assevera que no campo do currículo o discurso educacional caminhava focado em responder à pergunta "como?", isto é, qual o meio mais adequado para se transmitir conhecimento ou de adequar comportamentos de acordo com os interesses sociais? É justamente nesse mote que Apple vai sugerir que educação e currículo busquem trazer outras indagações, tais como: “o quê?" e "para quem?", já que estas indagações não enxergam o conhecimento e as práticas educacionais como dadas, mas sim como uma realidade a ser observada à luz de uma visão crítica, desvinculando-se, assim, da concepção predominante naquele momento histórico acerca de currículo.

Diante da proposta lançada no presente estudo, tem-se que é premente que se saia da visão quase que absolutamente tecnicista, que ainda faz parte de um quantitativo significativo dos cursos jurídicos para se caminhar em direção a uma visão mais humanística, com valorização da práxis participativa e do diálogo. Portanto, como consequência dessa vertente, está a influência que o currículo assume também na política de formação de professores, o que mostra a relevância do que já fora trabalhado anteriormente, quando se demonstrou ser imperioso, nesse cenário, a presença de "professores intelectuais".

Assim, vê-se que é preciso romper várias barreiras existentes para ressignificar a formação do profissional do Direito, já que vivemos em um cenário no qual os cursos jurídicos apresentam um perfil distanciado da realidade, afastando o estudante dos anseios sociais, em que os currículos implementados levam, muitas vezes, os mesmos a serem meros reprodutores de leis e doutrinas e não pessoas capazes de questionar o contexto no qual se insere.

O ensino do Direito não pode caminhar em descompasso com os valores do Estado democrático, que prima, acima de tudo, pela transformação social (GONÇALVES, SANTOS, 2013), pela redução das desigualdades regionais e nacionais, pela diminuição da pobreza e da marginalização (Constituição Federal, Art. $3^{\circ}$ ). Ele precisa superar a tradicional concepção positivista para dar espaço a um processo de aprendizagem multilateral, em que todos os envolvidos possuam consciência do papel que exercem no mundo e na construção coletiva do 
conhecimento, pois a partir de um “[...] processo dialético de aprendizado, que é construído, e não dado, e voltado para a solução dos problemas que a vida apresenta, o ensino jurídico poderá colaborar com a emancipação da sociedade" (GONÇALVES; SANTOS, 2013).

Assim, para que se possa pensar em uma formação cidadã, é imprescindível avançar de forma que se busque romper as inúmeras barreiras existentes nos modos de se propagar o conhecimento, sejam essas barreiras ideológicas, políticas, dentre tantas outras que se entrelaçam, quase que imperceptivelmente, e exercem influência no processo educacional.

Seguindo essa vertente, após as reflexões mais teóricas aqui difundidas acerca do currículo, passar-se-á, a seguir, a aprofundar considerações sobre o currículo que se defende como mais adequado para o ensino jurídico, a saber, com sustentação nos fundamentos dos Direitos Humanos.

\section{OS CURRÍCULOS JURÌDICOS À LUZ DA EDUCAÇÃO EM DIREITOS HUMANOS}

Neste momento, busca-se apresentar os elos que devem ser indissociáveis entre currículo e Educação em Direitos Humanos, a fim de possibilitar a abertura da interlocução na seara dos cursos jurídicos, reforçando a ideia da necessidade de uma formação cidadã para tais estudantes, no intuito de que se tornem, além de profissionais do Direito, agentes que atuem na proteção e na defesa da dignidade humana como valor fundante de uma ética e de uma moral.

Nesse diapasão deve-se fazer menção ao que é disposto pelo Programa Mundial de Educação em Direitos Humanos, quando enfatiza que "[...] a educação em direitos humanos promove uma abordagem à educação em direitos e deve ser compreendida como um processo", que abarca:

(a)'Direitos humanos através da educação': assegurando que todos os componentes e processos de aprendizagem, incluindo currículos, materiais, métodos e treinamento, conduzam ao aprendizado dos direitos humanos;

(b) 'Direitos humanos em educação': assegurando o respeito aos direitos humanos de todos os agentes e a prática dos direitos dentro do sistema educacional. (ONU, 2005, p. 7).

Assim, dentro dessa conjuntura, a Declaração das Nações Unidas sobre Educação e Formação em matéria de Direitos Humanos ${ }^{1}$, conceitua, em seu artigo $2^{\circ}$, a educação em direitos humanos como:

1. La educación y la formación em materia de derechos humanos están integradas por el conjunto de actividades educativas y de formación, información, sensibilización y aprendizaje que tienen por objeto promover el respeto universal $\mathrm{y}$ efectivo de todos los derechos humanos y las libertades fundamentales, contribuyendo así, entre otras cosas, a la prevención de los abusos y violaciones de los derechos humanos al proporcionar a las personas conocimientos, capacidades y comprensión y desarrollar sus actitudes y comportamientos para que puedan contribuir a la creación y promoción de una cultura universal de derechos humanos.

2. La educación y la formación em materia de derechos humanos engloban: a) La educación sobre los derechos bumanos, que incluye facilitar el conocimiento y la comprensión de las normas y principios de derechos humanos, los valores que los sostienen y los mecanismos que los protegen; b) La educación por medio de los derechos bumanos, que incluye aprender y enseñar respetando los derechos de los

\footnotetext{
1 A referida Declaração foi devidamente aprovada pela Assembleia Geral da ONU, em 23 de março de 2011.
} 
educadores y los educandos; c) La educación para los derechos humanos, que incluye facultar a las personas para que disfruten de sus derechos y lo se ejerzan, y respeten y defiéndanlos de los demás (ONU, 2011).

Observa-se que a educação em direitos humanos necessita da constante indissociabilidade entre ensino, pesquisa e extensão, bem como de currículos que privilegiem toda essa transversalidade, perpassando por todo seu desenho formal o que já se acentuou, anteriormente, acerca da interdisciplinaridade, da multidisciplinaridade e da transdisciplinaridade.

Ao se defender uma educação com a abrangência acima descrita, pode-se fazer a apropriação do que expressa Morin (2005, p. 23), quando diz que:

[...] a reforma necessária do pensamento é aquela que gera um pensamento do contexto e do complexo. O pensamento contextual busca sempre a relação de inseparabilidade e as inter-retroações entre qualquer fenômeno e seu contexto, e deste com o contexto planetário. O complexo requer um pensamento que capte relações, inter-relações, implicações mútuas, fenômenos multidimensionais, realidades que são simultaneamente solidárias e conflitivas (como a própria democracia, que é o sistema que se nutre de antagonismos e que, simultaneamente, os regula), que respeitem a diversidade, ao mesmo tempo que a unidade, um pensamento organizador que conceba a relação recíproca entre todas as partes.

Nessa dinâmica, é necessário ressaltar mais uma vez o papel do docente como um elo substancial na construção de todo esse processo, o qual guiará o aluno, fazendo-o buscar a interação com os problemas reiterados na perspectiva de seu contexto, elegendo metodologias dialógicas e práticas, em uma tarefa que propicie ao estudante saber o porquê daquela realidade e, simultaneamente, reveja, a cada situação, o seu verdadeiro papel, em uma troca de experiências que leva ao amadurecimento cognitivo de ambas as partes.

Trazendo à cena novamente Freire (1987, p. 44):

Quando tentamos um adentramento no diálogo, como fenômeno humano, se nos revela algo que já podemos dizer ser ele mesmo: a palavra. Mas, ao encontrarmos a palavra, na análise do diálogo, como algo mais que um meio para que ele se faça, se nos impõe buscar, também, seus elementos constitutivos. Esta busca nos leva a surpreender, nela, duas dimensões; ação e reflexão, de tal forma solidárias, em uma interação tão radical que, sacrificada, ainda que em parte, uma delas, se ressente, imediatamente, a outra. Não há palavra verdadeira que não seja práxis. Daí, que dizer a palavra verdadeira seja transformar o mundo. A palavra inautêntica, por outro lado, com que não se pode transformar a realidade, resulta da dicotomia que se estabelece entre seus elementos constituintes. Assim é que, esgotada a palavra de sua dimensão de ação, sacrificada, automaticamente, a reflexão também se transforma em palavraria, verbalismo, blábláblá. Por tudo isto, alienada e alienante. É uma palavra oca, da qual não se pode esperar a denúncia do mundo, pois não há denúncia verdadeira, sem compromisso de transformação, nem este sem ação.

Nesta visão e de acordo com o preceituado por Silva (2014, p. 10), a metodologia em direitos humanos “[...] deve partir da realidade dos alunos, ensiná-los a investigá-la, a problematizála de modo crítico, mas também com afeto, com solidariedade, envolvendo todos os atores nessa educação."

Para tanto, o currículo volta a ser o grande desafio a ser vencido, pois, enquanto se pensar na construção de currículos para atender interesses outros que não o de uma educação 
verdadeiramente cidadã, certamente haverá uma proliferação desenfreada de profissionais que entendam que a posição de destaque ocupada aliada ao esoterismo da linguagem, peculiar ao universo jurídico, devam preponderar sobre a natureza do ministério que merece realmente permear a profissão, contentando-se com os excelentes salários, capazes de garantir uma vida de ostentação, em detrimento do sentido determinante das suas ações profissionais.

Quando se diz que o currículo é um desafio a ser vencido, faz-se a afirmação tendo por base tudo que fora discorrido sobre as relações que o circundam, tais como poder, força, ideologia etc. Afinal, como muito bem ressalta Magendzo (2006, p. 37):

Diseñar y elaborar currículum, en especial el referido a derechos humanos, requiere "negociar saberes", sin claudicar em principios irrenunciables, buscar consensos en las diferencias, tarea que como todos sabemos no es del todo sencilla, ya que está de por medio el poder y el control sobre el conocimiento curricular. Además de los especialistas y profesores, participan empresarios, trabajadores, padres y madres de familia, apoderados, miembros de la comunidad, estudiantes, etc. Existe, por así decir, una heterogeneidad de actores con percepciones, intereses y valores culturales diversos y a veces antagónicos frente a la cultura que se expresan en el currículum.

Assim, incutir os direitos humanos no segmento da educação formal em uma sociedade como a brasileira, com fortes raízes de autoritarismo e escravidão, traz, inevitavelmente, a disputa que se atrela aos campos do saber e do poder.

Como já se sustentou no início desta seção, não há neutralidade ao se falar em construção curricular e no caso da educação em direitos humanos a situação não difere, eis que, conforme destacado por Magendzo (2006, p. 36):

[...] Existe una exigencia ética por develar el juego de intereses, ideologías y visiones de mundo diferentes, discrepantes y a veces antagónicas que subyacen en la toma de las decisiones curriculares. [...] Implícito, y por so obvio, es que diseñar currículum significa seleccionar conocimiento: conceptos, habilidades, destrezas, actitudes, valores. Es imposible incorporar todo el conocimiento existente al currículum. Si esto fuera posible no existiría la necesidad de hacer currículum. La tarea de selección y organización del conocimiento es la tarea del diseño curricular. Este proceso no es, por supuesto, una tarea neutra y tampoco simples.

Dentro dessa ordem de ideias, vê-se que apesar de ser o currículo um campo de disputa ideológica, política, cultural, não se pode abrir mão da sua construção com elementos que subsidiem a visão holística embasado no gozo destes direitos, que abrange tanto os direitos humanos no contexto educativo, isto é, conseguir que todos os componentes e processos de aprendizagem, incluindo os planos de estudo, o material didático, os métodos pedagógicos e a capacitação, conduzam ao aprendizado dos direitos humanos, por um lado, e a realização dos direitos humanos na educação, por outro lado, que consiste em fazer valer o respeito dos direitos humanos de todos os membros da comunidade escolar. (UNESCO, 2006). Nesse prisma, os currículos para o os cursos de Direito devem apresentar a sensibilidade de conseguir contemplar as especificidades de cada área, sem deixar de dar conta dos conhecimentos imprescindíveis àqueles que terão em mãos, muitas vezes, o poder de decidir futuros e de julgar vidas.

Aqueles que se revestem de "poder", estando legitimados, em nome do próprio Estado, por um cargo que os respaldam a dar respostas a todos que recorrem ao aparato jurisdicional, tentando ver sanada ou minimizada uma iniquidade, tem o dever de fazer prevalecer a tão sonhada Justiça. 
De nada adianta uma formação estruturada nas vertentes mais modernas do Direito e de todas as fragmentações daí decorrentes, se é esquecida ou minimizada a preparação humanística dos profissionais que atuarão no cenário jurídico-social.

O Direito, regulado por um conjunto de regras normativas, pode servir para respaldar decisões que estão em acordo com o que é "legislado", mas que, ao mesmo tempo, não encontra guarida no senso ético da moralidade. Em outras palavras, quer-se dizer que o Direito, formalmente falando, pode, muitas vezes, encobrir atos injustos e desumanos, legitimados tão somente por estarem em conformidade com os ditames legais.

Assim como os currículos, as leis são redigidas e promulgadas em contextos que se permeiam por interesses das mais variadas naturezas. Não é raro encontrar julgados que estão em perfeita consonância com o que está "codificado", mas que não resistem a um olhar moral mais criterioso. E o cerne para se buscar ressignificar essa realidade tem sua ligação à formação dos estudantes.

Antes de se pensar no conhecimento que se vai transmitir, primeiro deve-se perguntar: qual o profissional que necessita ser formado?

Nas exatas palavras de Mészáros (2008, p. 47):

A grande questão é: o que aprendemos de uma forma ou de outra? Será que a aprendizagem conduz à autorrealização dos indivíduos como "indivíduos socialmente ricos" humanamente, ou está ela a serviço da perpetuação consciente ou não, da ordem social alienante e definitivamente incontrolável do capital?

Não se torna excessivo delinear aqui, dentro das ideias já defendidas, o que ensina Frigotto (2003, p. 31), ao abordar as práticas educativas no modelo neoliberal, enfatizando que:

A qualificação humana diz respeito ao desenvolvimento de condições físicas, mentais, afetivas, estéticas e lúdicas do ser humano (condições omnilaterais) capazes de ampliar a capacidade de trabalho na produção de valores de uso em geral como condição de satisfação das múltiplas necessidades do ser humano no seu devenir histórico. Está, pois, no plano dos direitos que não podem ser mercantilizados e, quando isso ocorre, agride-se elementarmente a própria condição humana.

Por tal razão, defende-se um currículo para os cursos de Direito com as bases aqui declinadas, com um olhar para o humano que o enxergue como humano, com uma visão da realidade decalcada dos aportes que norteiam a verdadeira conjuntura, sem as ilusões de que se preparar um bom profissional é apenas torná-lo apto a ocupar um cargo público de grande magnitude ou ser um advogado bem sucedido em termos financeiros.

\section{A REALIDADE DOS CURRÍCULOS DOS CURSOS DE DIREITO NO ESTADO DE ALAGOAS}

Seguindo o que preceitua Bardin (2016), ao estabelecer que na fase de pré-análise, em que se dá a escolha dos documentos que comporão o corpus da pesquisa, o pesquisador deve se atentar para cumprir as regras da exaustividade, que exige que nenhum documento deve ser deixado de fora; a regra da homogeneidade, que disciplina que a seleção dos documentos deva ter o mesmo tema para que permita a comparação e a regra da pertinência, que ressalta que os documentos devam guardar correlação com os objetivos da análise, buscou-se analisar os currículos de todos os cursos de Direito do estado de Alagoas. 
Entretanto, convém explicitar que dos 19 cursos existentes no estado, só não se conseguiu acesso a uma matriz curricular, eis que a mesma não se encontra disponibilizada no sítio eletrônico da IES ${ }^{2}$. Ressalta-se, ainda, que buscando o acesso ao referido documento, estabeleceu-se contato telefônico com a secretaria da instituição que informou que a "grade" só era fornecida a alunos regularmente matriculados.

Por outro lado, com obtenção das matrizes curriculares dos outros 18 cursos, chega-se a um percentual de $94,7 \%$ do corpus que será analisado, o que já representa um montante bem significativo, além de que as diretrizes metodológicas adotadas neste trabalho dispensam o levantamento de todo universo pesquisado, já que o fulcro das reflexões aqui lançadas não é estatístico.

Optou-se neste estudo por não citar nominalmente cada IES nas análises a seguir realizadas, preservando assim a identidade e imagem das referidas instituições de ensino.

Dessa forma, quando for necessário apresentar os nomes das instituições, far-se-á uso de nomes fictícios, tendo se escolhido para cada IES o nome de um deus grego do Olimpo.

Ainda a título de esclarecimento, fundamental destacar que a primeira fase da análise se deu no intuito de contemplar a presença ou ausência específica da disciplina direitos humanos nos 18 currículos já mencionados. Após tal análise, buscou-se contemplar se, nas instituições que apresentam a disciplina em seus currículos, a oferta se dá como disciplina obrigatória ou eletiva, bem como a carga horária que é dedicada a mesma. Por fim, ampliou-se a visão e, consequentemente a análise, para cotejar a proporção que a disciplina representa em relação à carga total da matriz curricular, assim como a relação que as disciplinas humanísticas constituem em contraponto às disciplinas chamadas de técnico-jurídicas.

Dessa forma, com tais critérios estabelecidos, chegou-se aos dados que serão a seguir pormenorizados.

Dos 18 currículos estudados, constatou-se a presença da disciplina Direitos Humanos em dez, assim como se verificou a presença da disciplina como eletiva em um currículo, na modalidade online, chegando-se, ainda, a sete currículos que não apresentam, nem em caráter obrigatório nem eletivo, a disciplina Direitos Humanos.

Para melhor compreensão do que fora encontrado, apresentar-se-á a tabela a seguir.

Tabela 1: Oferta (ou não) da disciplina de Direitos Humanos pelas instituições de ensino superior de Direito em Alagoas ${ }^{3}$ :

\begin{tabular}{c|c|c}
\hline $\begin{array}{c}\text { Nome da instituição de ensino } \\
\text { superior }\end{array}$ & Disciplina Direitos Humanos & Carga horária da disciplina \\
\hline ATENA & Disciplina Obrigatória & $40 \mathrm{~h}$ \\
\hline HADES & Disciplina Obrigatória & $60 \mathrm{~h}$ \\
\hline CRIO & Disciplina Obrigatória & $60 \mathrm{~h}$ \\
\hline DEMÉTER & Disciplina Obrigatória & $40 \mathrm{~h}$ \\
\hline DIONÍSIO & Disciplina Obrigatória & $80 \mathrm{~h}$ \\
\hline EROS & Disciplina Obrigatória & $40 \mathrm{~h}$ \\
\hline HEFESTO & Disciplina Obrigatória & $40 \mathrm{~h}$ \\
\hline HERMES & Disciplina Obrigatória & $40 \mathrm{~h}$ \\
\hline APOLO & Disciplina Obrigatória & $30 \mathrm{~h}$ \\
\hline
\end{tabular}

\footnotetext{
2 Importante esclarecer que os referidos currículos são documentos de domínio público, já que as instituições são obrigadas pelo Ministério da Educação a disponibilizá-los em suas páginas eletrônicas.

${ }^{3}$ Ressalta-se que procurou destacar na cor verde as instituições que realizam a oferta como disciplina obrigatória, em amarelo a que realiza como eletiva e em azul as instituições que não contemplam em seus currículos a disciplina objeto da investigação.
} 
DOI: $10.12957 /$ teias.\%Y.49496

\begin{tabular}{c|c|c}
\hline ÁRTEMIS & Disciplina Obrigatória & $30 \mathrm{~h}$ \\
\hline POSEIDON & Disciplina Eletiva & $36 \mathrm{~h}$ \\
\hline ZEUS & Não existe a Disciplina & $0 \mathrm{~h}$ \\
\hline HERA & Não existe a Disciplina & $0 \mathrm{~h}$ \\
\hline CRATOS & Não existe a Disciplina & $0 \mathrm{~h}$ \\
\hline AFRODITE & Não existe a Disciplina & $0 \mathrm{~h}$ \\
\hline ARES & Não existe a Disciplina & $0 \mathrm{~h}$ \\
\hline REIA & Não existe a Disciplina & $0 \mathrm{~h}$ \\
\hline DIONE & Não existe a Disciplina & $0 \mathrm{~h}$ \\
\hline
\end{tabular}

Fonte: Ministério da Educação - Sistema e-MEC, 2018.

Para ter-se uma visão da realidade já demonstrada sob uma forma mais representativa, lançou-se mão do gráfico apresentado adiante.

Figura 1: Análise da disciplina de Direitos Humanos nos currículos dos cursos de Direito do estado de Alagoas

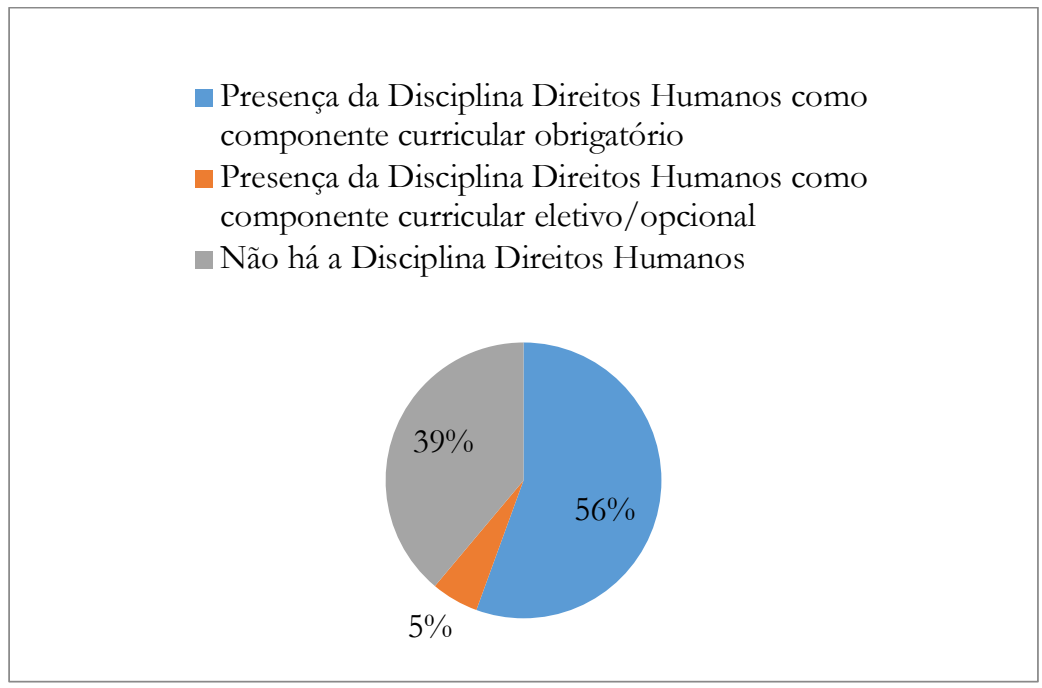

Fonte: Ministério da Educação - Sistema e-MEC, 2018.

Os dados revelam que há um percentual alto de instituições que não incluíram a disciplina Direitos Humanos em seus currículos formais. Dentre as que contemplam a disciplina nos seus currículos, indispensável se torna avaliar qual a proporção da carga horária destinada à mesma quando comparada ao montante da carga horária total do curso, conforme apresentado adiante.

Tabela 2: Carga horária destinada à disciplina Direitos Humanos

\begin{tabular}{c|c|c}
\hline $\begin{array}{c}\text { Nome da instituição de ensino } \\
\text { superior }\end{array}$ & Carga horária da disciplina & Carga horária total do curso \\
\hline ATENA & $40 \mathrm{~h}$ & $4.080 \mathrm{~h}$ \\
\hline HADES & $60 \mathrm{~h}$ & $4.440 \mathrm{~h}$ \\
\hline CRIO & $60 \mathrm{~h}$ & $4.440 \mathrm{~h}$ \\
\hline DEMÉTER & $40 \mathrm{~h}$ & $3.980 \mathrm{~h}$ \\
\hline DIONÍSIO & $80 \mathrm{~h}$ & $4.320 \mathrm{~h}$ \\
\hline EROS & $40 \mathrm{~h}$ & $4.360 \mathrm{~h}$ \\
\hline HEFESTO & $40 \mathrm{~h}$ & $3.700 \mathrm{~h}$ \\
\hline HERMES & $40 \mathrm{~h}$ & $3.700 \mathrm{~h}$ \\
\hline
\end{tabular}




\begin{tabular}{c|c|c}
\hline APOLO & $30 \mathrm{~h}$ & $3.720 \mathrm{~h}$ \\
\hline ÁRTEMIS & $30 \mathrm{~h}$ & $3.720 \mathrm{~h}$ \\
\hline POSEIDON & $36 \mathrm{~h}$ & $3.784 \mathrm{~h}$ \\
\hline
\end{tabular}

Fonte: Ministério da Educação - Sistema e-MEC, 2018.

Nesse sentido, constatou-se que há uma ínfima destinação de horas, para não dizer desprezível, à disciplina de Direitos Humanos por parte das instituições de ensino superior que ofertam o curso de Direito em Alagoas. Os currículos mostraram que a instituição que mais dimensiona a disciplina o faz em uma proporção de apenas 1,85\% de seu currículo global. Há, inclusive, instituições que não atingem sequer $1 \%$ desse montante.

Partindo para um olhar mais amplo e buscando analisar também a forma como se dá a configuração da vertente humanística nesses currículos, percebeu-se que das 18 instituições estudadas, apenas seis apresentam número igual ou maior a $5 \%$ de sua carga total destinada às disciplinas propedêuticas. Assim, diante do alto quantitativo de disciplinas técnico-jurídicas encontradas em todos os currículos, pode-se inferir que a proporção que dedicam à formação humanística é insuficiente ao perfil profissional que se defende neste trabalho.

\section{O QUE REVELAM OS DADOS DO ENADE EM RELAÇÃO AOS ELEMENTOS CURRICULARES DOS DIREITOS HUMANOS NOS CURSOS DE DIREITO EM ALAGOAS?}

Buscando-se uma maior consolidação acerca do que se vem trabalhando ao longo deste estudo, entendeu-se imperioso observar não só os currículos dos cursos de Direito no estado de Alagoas, mas também como acontecem os reflexos das formações emanadas desses cursos em uma avaliação de caráter global, analisando-se, para tanto, os resultados do Exame Nacional de Desempenho dos Estudantes (ENADE), que avalia o rendimento dos alunos dos cursos de graduação em relação aos conteúdos programáticos dos cursos em que estão matriculados.

Achou-se oportuno trabalhar os referidos dados, eis que, independentemente de críticas existentes acerca da formatação e desenvolvimento desse método avaliativo, o mesmo representa, até os dias contemporâneos, o parâmetro utilizado para quantificar os rendimentos os alunos e, consequentemente, das instituições de ensino superior do país, servindo, inclusive, de base para as respectivas notas institucionais.

Deve-se esclarecer que a análise se deu, em um primeiro momento, a partir das provas do ENADE dos quatro últimos ciclos avaliativos disponíveis nos bancos de dados do INEP, a saber: 2006, 2009, 2012 e 2015.

De forma inicial, buscou-se mapear o número de cursos de Direito participantes do ENADE, saindo-se do quadro mais geral, chegando-se à realidade específica objeto da presente investigação, ou seja, fazendo tal rastreamento não só na região Nordeste como também no estado de Alagoas, passando-se a visualizar também a distribuição dos valores e pesos para cálculos da nota entre os componentes da prova (formação geral e componente específico), caminhando no sentido de realizar um dimensionamento das questões de formação geral com abordagem direta e/ou indireta dos direitos humanos, ao longo das edições ENADE aqui trabalhadas, encontrando o dimensionamento quantitativo das questões de formação geral especificamente nos cursos de Direito.

A posteriori, indo ao ponto central da pesquisa, passou-se a avaliar a consolidação do desempenho dos concluintes dos cursos de Direito ofertados pelas IES de Alagoas nas questões de formação geral com abordagem, direta ou indireta, de direitos humanos. Importante esclarecer 
que, para cada situação acima descrita, foi feita a série histórica dos anos aqui trabalhados, passando-se a obter os dados apresentados abaixo.

Tabela 3: Número de cursos de Direito participantes do ENADE, por organização acadêmica, na região Nordeste e no estado de Alagoas

\begin{tabular}{|l|c|c|c|c|c|c|c|c|}
\hline \multirow{2}{*}{$\begin{array}{l}\text { Organização } \\
\text { Acadêmica }\end{array}$} & \multicolumn{4}{|c|}{ REGIÃO NORDESTE } & \multicolumn{3}{c|}{ ESTADO DE ALAGOAS } \\
\cline { 2 - 9 } & $\mathbf{2 0 0 6}$ & $\mathbf{2 0 0 9}$ & $\mathbf{2 0 1 2}$ & $\mathbf{2 0 1 5}$ & $\mathbf{2 0 0 6}$ & $\mathbf{2 0 0 9}$ & $\mathbf{2 0 1 2}$ & $\mathbf{2 0 1 5}$ \\
\hline Universidade & 42 & 45 & 47 & 57 & 1 & 2 & 2 & 2 \\
\hline Centro Universitário & 5 & 4 & 6 & 12 & 1 & 1 & 1 & 2 \\
\hline Faculdades & 99 & 138 & 130 & 139 & 6 & 11 & 11 & 12 \\
\hline TOTAL & 142 & 187 & 183 & 208 & 8 & 14 & 14 & 16 \\
\hline
\end{tabular}

Fonte: Inep (2018).

Pela tabela acima, percebe-se um incremento no número de faculdades de Direito participantes do ENADE em cada novo ciclo avaliativo, o que é, indubitavelmente, reflexo da expansão do ensino superior privado e que, na área do ensino jurídico, ocorre com intensidade significativa.

Tabela 4: Distribuição dos pesos entre os componentes da prova (formação geral e componente específico) e no cálculo da nota ENADE

\begin{tabular}{|l|c|c|c|}
\hline \multicolumn{1}{|c|}{ Partes } & $\begin{array}{c}\text { Número } \\
\text { de } \\
\text { questões }\end{array}$ & $\begin{array}{c}\text { Peso das } \\
\text { questões no } \\
\text { componente (\%) }\end{array}$ & $\begin{array}{c}\text { Peso dos } \\
\text { componentes no } \\
\text { cálculo da nota (\%) }\end{array}$ \\
\hline $\begin{array}{l}\text { Formação Geral/ Questões } \\
\text { Objetivas }\end{array}$ & 08 & 60 & \multirow{2}{*}{25} \\
\hline $\begin{array}{l}\text { Formação Geral/ Questões } \\
\text { Discursivas }\end{array}$ & 02 & 40 & 75 \\
\hline $\begin{array}{l}\text { Componente Específico/ Questões } \\
\text { Objetivas }\end{array}$ & 27 & 85 & 700 \\
\hline $\begin{array}{l}\text { Componente Específico/ Questões } \\
\text { discursivas }\end{array}$ & 03 & 15 & 100 \\
\hline TOTAL & 40 & --- & \\
\hline
\end{tabular}

Fonte: Inep (2018).

As informações constantes da Tabela 4 têm apenas o intuito de melhor situar o leitor, ajudando a entender como se dá a ponderação dos critérios distributivos das questões entre os eixos de formação geral e específica, a fim de se obter a nota avaliativa final, já que, posteriormente, apresentar-se-á tais valores. 
Tabela 5: Dimensionamento das questões de formação geral com abordagem direta e/ou indireta de direitos humanos, ao longo das edições $\operatorname{ENADE~(2006,~2009,~} 2012$ e 2015)

\begin{tabular}{|l|c|c|c|c|}
\hline & 2006 & 2009 & 2012 & 2015 \\
\hline Questão Objetiva 1 & NÃO & SIM & NÃO & SIM \\
\hline Questão Objetiva 2 & NÃO & SIM & SIM & SIM \\
\hline Questão Objetiva 3 & SIM & SIM & SIM & SIM \\
\hline Questão Objetiva 4 & SIM & SIM & SIM & SIM \\
\hline Questão Objetiva 5 & NÃO & SIM & NÃO & NÃO \\
\hline Questão Objetiva 6 & NÃO & NÃO & NÃO & SIM \\
\hline Questão Objetiva 7 & NÃO & NÃO & SIM & NÃO \\
\hline Questão Objetiva 8 & NÃO & SIM & NÃO & SIM \\
\hline Questão Discursiva 1 & SIM & NÃO & NÃO & SIM \\
\hline Questão Discursiva 2 & SIM & SIM & SIM & SIM \\
\hline TOTAL & 04 & 07 & 05 & 08 \\
\hline
\end{tabular}

Fonte: Inep (2018).

Pela tabela ora exposta, percebe-se uma quantidade satisfatória e, em alguns momentos, até crescente de questões que guardam correlação direta ou indiretamente com os conteúdos que fazem parte de todo grande leque abarcado pelos direitos humanos, o que, por si só, já justificaria a presença dos conteúdos de forma mais acentuada nos currículos dos cursos de Direito do estado de Alagoas.

Se observarmos os valores ora apresentados, em dados percentuais, ter-se-á o que se visualizará nas tabelas seguintes, nas quais se mostra o dimensionamento quantitativo das questões e a abordagem dos direitos humanos nas edições do ENADE aqui trabalhadas.

Tabela 6: Dimensionamento quantitativo das questões de formação geral ao longo das edições ENADE nos cursos de Direito

\begin{tabular}{|l|c|c|c|c|c|c|c|c|}
\hline \multirow{2}{*}{ Partes } & \multicolumn{2}{|c|}{2006} & \multicolumn{2}{c|}{2009} & \multicolumn{2}{c|}{2012} & \multicolumn{2}{c|}{2015} \\
\cline { 2 - 9 } & $\mathbf{n}$ & $\%$ & $\mathbf{n}$ & $\%$ & $\mathbf{n}$ & $\%$ & $\mathbf{n}$ & $\%$ \\
\hline $\begin{array}{l}\text { Formação Geral/ } \\
\text { Questões Objetivas }\end{array}$ & 02 & 20 & 01 & 10 & 01 & 10 & 02 & 20 \\
\hline $\begin{array}{l}\text { Formação Geral/ } \\
\text { Questões Discursivas }\end{array}$ & 02 & 20 & 06 & 60 & 04 & 40 & 06 & 60 \\
\hline TOTAL & 04 & 40 & 07 & 70 & 05 & 50 & 08 & 80 \\
\hline
\end{tabular}

Fonte: Inep (2018). 
Tabela 7: Abordagem de direitos humanos nas questões de formação geral ao longo das edições do ENADE no curso de Direito

\begin{tabular}{|l|c|c|c|c|c|c|c|c|c|}
\hline \multirow{2}{*}{ Partes } & \multirow{2}{*}{$\begin{array}{c}\text { N. de } \\
\text { questões }\end{array}$} & \multicolumn{2}{|c|}{2006} & \multicolumn{2}{|c|}{2009} & \multicolumn{2}{|c|}{2012} & \multicolumn{2}{|c|}{2015} \\
\cline { 3 - 10 } & $\mathbf{n}$ & $\mathbf{0}$ & $\mathbf{n}$ & $\mathbf{\%}$ & $\mathbf{n}$ & $\mathbf{\%}$ & $\mathbf{n}$ & $\%$ \\
\hline $\begin{array}{l}\text { Formação Geral/ } \\
\text { Questões } \\
\text { Objetivas }\end{array}$ & 08 & 02 & 25 & 06 & 75 & 04 & 50 & 06 & 75 \\
\hline $\begin{array}{l}\text { Formação Geral/ } \\
\text { Questões } \\
\text { Discursivas }\end{array}$ & 02 & 02 & 100 & 01 & 50 & 01 & 50 & 02 & 100 \\
\hline
\end{tabular}

Fonte: Inep (2018).

Partindo-se à observação do desempenho dos estudantes concluintes dos cursos de Direito das instituições de ensino superior do estado de Alagoas, nas questões de formação geral com abordagem aos direitos humanos, tem-se o resultado configurado na Tabela 7:

Tabela 7: Consolidação do desempenho dos concluintes participantes de Direito ofertados pelas IES de Alagoas nas questões de formação geral com abordagem, direta ou indireta, de direitos humanos

\begin{tabular}{|l|c|c|c|c|c|c|c|c|c|c|c|c|}
\hline \multirow{2}{*}{$\begin{array}{c}\text { Desempenho } \\
\text { médio }\end{array}$} & \multicolumn{3}{|c|}{2006} & \multicolumn{3}{c|}{2009} & \multicolumn{3}{c|}{2012} & \multicolumn{3}{c|}{2015} \\
\cline { 2 - 13 } & AL & NE & BR & AL & NE & BR & AL & NE & BR & AL & NE & BR \\
\hline $\begin{array}{l}\text { Questões } \\
\text { objetivas }\end{array}$ & 57,6 & 61,2 & 58,3 & 51,9 & 58,1 & 56,8 & 50,9 & 53,7 & 53,1 & 54,9 & 56,7 & 56,7 \\
\hline $\begin{array}{l}\text { Questões } \\
\text { discursivas }\end{array}$ & 52,2 & 55,6 & 53,5 & 36,5 & 28,3 & 32,8 & 43,1 & 43,1 & 45,0 & 56,5 & 62,0 & 62,9 \\
\hline Média geral & 54,9 & 58,4 & 55,9 & 44,2 & 43,2 & 44,8 & 47,0 & 48,4 & 49,1 & 55,7 & 59,4 & 59,8 \\
\hline
\end{tabular}

Fonte: Inep (2018).

Os dados mostram que os estudantes dos cursos de Direito do estado de Alagoas quase sempre apresentam os piores rendimentos avaliativos no tocante à formação em direitos humanos, tanto quando comparados à região Nordeste, como também ao panorama brasileiro de forma global.

Isso só reforça tudo que foi minuciosamente discorrido neste estudo acerca da pouca formação humanística observada nos currículos dos cursos de Direito ofertados em Alagoas, os quais parecem assumir, cada vez mais, uma feição tecnicista em detrimento dos verdadeiros valores em torno de questões centrais como justiça, ética e cidadania.

\section{CONCLUSÃO}

Após tudo que fora declinado, levando em conta o referencial teórico esboçado no presente estudo, tanto em relação à educação em direitos humanos como no tocante especificamente ao currículo, e tendo ainda por base os dados levantados nos 18 currículos dos cursos de Direito de Alagoas e nos dados concernentes ao desempenho dos últimos quatro ciclos avaliativos no ENADE dos cursos de Direito do estado de Alagoas, pode-se, a partir do que Bardin (2016) chama 
de triangulação dos dados, inferir que o ensino jurídico alagoano caminha em descompasso aos ditames da educação em direitos humanos, encontrando-se na contramão de uma formação verdadeiramente cidadã.

Tem-se assim uma verdadeira banalização curricular no ensino jurídico.

Sabe-se que o transcurso do ensino jurídico no Brasil é consequência de um modelo atrelado ao Estado e, consequentemente, o Estado, por sua vez, é reflexo dos modelos políticos advindos das investidas modernas, o que acarreta um perfil curricular positivista que, de forma geral, plasmou e plasma a maioria das instituições de ensino superior, fazendo com que os direitos humanos se apresentam nos currículos como um subtema da ciência jurídica, ou, um tema "banal". E, por ser banalizado, o currículo se depara com o problema da justiça, compreendida aqui como legitimidade dos direitos humanos.

Diante da referida "banalização", os direitos humanos são apenas normas e a educação a transmissão de normas e conceitos. Assim, o educar não passa de uma equação de fatos aplicados ao trivial mundo de papel, um discurso que pensa o papel e não o mundo, é só um discurso pelo discurso, um esquecimento do ser que se perde no papel.

O que se pensou nesse estudo não foi um processo que entende tão somente o poder da letra nas linhas das leis e das ciências, mas que essas letras das leis e das ciências são indubitavelmente humanas. Isso não significa uma exclusão do tecnicismo jurídico, mas um deslocamento do seu eixo, a saber: primeiro o humano, depois o científico e o técnico. Formar profissionais para exercício da cidadania e repensar o ensino dos direitos humanos é uma abertura de reflexão, é fazer com que a educação seja capaz de tornar-se essencial nesse humano adormecido pela técnica. É preciso compreender que o que motivou essa pesquisa foi a necessidade de se pensar um outro pensar. E esse outro pensar dos direitos humanos é o pensar pedagógico. A norma só é norma porque é ensinada, faz-se necessário compreender que essa centelha não é uma "novidade" do ensino jurídico, mas o contrário, é permitir que esse ensino seja o desvelamento do "outro".

Assim, com essa reflexão, espera-se despertar novos olhares sobre a educação jurídica alagoana, acreditando que é possível pensar o ensino dos direitos humanos para além do Direito positivo, já que o currículo, por ser produto da atividade humana, pode e deve ser repensado.

\section{REFERÊNCIAS}

APPLE, Michael W. Repensando ideologia e currículo. In: MOREIRA, Antonio Flávio; SILVA, Tomaz Tadeu da (orgs.). Currículo, cultura e sociedade. São Paulo: Cortez, 1999.

APPLE, Michael W. Ideologia e currículo. São Paulo: Ed. Brasiliense, 1982.

APPLE, Michael W. Educação e poder. Porto Alegre: Artes Médicas Sul, 1989.

BARDIN, Laurence. Análise de conteúdo. São Paulo: Edições 70, 2016.

BASTOS, Aurélio Wander. Os cursos jurídicos e as elites políticas brasileiras: ensaio sobre a criação dos cursos jurídicos. Brasília: Câmara dos Deputados, 1978.

BITTAR, Eduardo Carlos Bianca. Estudos sobre ensino jurídico: pesquisa, metodologia, diálogo e cidadania. São Paulo: Atlas, 2006.

BITTAR, Eduardo Carlos Bianca. Ética, educação, cidadania e direitos humanos: estudos filosóficos entre cosmopolitismo e responsabilidade social. São Paulo: Manoele, 2004.

BRASIL. Comitê Nacional de Educação em Direitos Humanos. Plano Nacional de Educação em Direitos Humanos. 2. tiragem, atualizada. Secretaria Especial dos Direitos Humanos. Presidência da República. Ministério da Educação. Ministério da Justiça. UNESCO, 2007. 
BRASIL. Ministério da Educação e Cultura. LDB - Lei n. 9.394/96, de 20 de dezembro de 1996. Estabelece as diretrizes e bases da educação nacional. Brasília: MEC, 1996.

BRASIL. Ministério da Educação e Cultura. Resolução n. 09/2004, de 29 de setembro de 2004. Institui as diretrizes curriculares nacionais do curso de graduação em Direito e dá outras providências. Brasília: MEC, 2004.

BRASIL. Ministério da Educação e Cultura. Resolução n. 02/2007, de 18 de junho de 2007. Dispõe sobre a carga horária mínima e procedimentos relativos à integralização e duração dos cursos de graduação, bacharelados, na modalidade presencial. Brasília: MEC, 2007.

FEITOSA NETO, Inácio José. O ensino jurídico brasileiro: uma análise dos discursos do MEC e da OAB. Recife: Ed. do Autor, 2007.

GIROUX, Henry A. Os professores como intelectuais: rumo a uma pedagogia crítica da aprendizagem. Porto Alegre: Artes Médicas, 1997.

GIROUX, Henry A. Escola crítica e política cultural. São Paulo: Cortez, 1988.

MAGENDZO, Abraham. Educación en derechos humanos - un desafío para los docentes de hoy. Santiago: LOM Ediciones, 2006.

MAGENDZO, Abraham. La educación em derechos humanos: reflexiones y retos para enfrentar un nuevo siglo. Disponível em www.iidh.org.br. Acesso em 17 jun. 2018.

MOREIRA, Antônio Flávio Barbosa; SILVA, Tomaz Tadeu da. Currículo, cultura e sociedade. São Paulo: Cortez, 1999.

MOREIRA, Antônio Flávio Barbosa (org.) Currículo: políticas e práticas. Campinas, São Paulo: Papirus, 1999.

PÉREZ-LUÑO, Antonio Enrique. La universidad de los derechos humanos y el Estado Constitucional. Bogotá: Universidad Externado de Colômbia, 2002. p. 23.

TARDIF, Maurice. Saberes docentes e formação profissional. Petrópolis, Rio de Janeiro: Vozes, 2012.

\section{Informações das autoras}

Lana Lisiêr de Lima Palmeira

Universidade Federal de Alagoas (UFAL)

E-mail: lanallpalmeira@outlook.com

ORCID: https://orcid.org/0000-0003-0443-7245

Link Lattes: http://lattes.cnpq.br/9538287578494559

Edna Cristina do Prado

Universidade Federal de Alagoas (UFAL)

E-mail:wiledna@uol.com.br

ORCID: https://orcid.org/0000-0001-8226-2466

Link Lattes: http://lattes.cnpq.br/8158728896858544

Carla Priscilla Barbosa Santos Cordeiro

Faculdade Cesmac do Agreste

E-mail: professoracarlapriscilla@gmail.com

ORCID: https://orcid.org/0000-0002-2806-6023

Link Lattes: http://lattes.cnpq.br/80448884748837865 